\title{
Participatory design and validation of mobility enhancement robotic wheelchair
}

\author{
Brandon Daveler, MS; ${ }^{1}$ Benjamin Salatin, MS; ${ }^{2}$ Garrett G. Grindle, MS $;^{1}$ Jorge Candiotti, BS; $^{1}$ Hongwu Wang, \\ PhD; ${ }^{1}$ Rory A. Cooper, PhD ${ }^{1^{*}}$ \\ ${ }^{1}$ Department of Rehabilitation Science and Technology, University of Pittsburgh, Pittsburgh, PA, and Human Engineering \\ Research Laboratories, Department of Veterans Affairs (VA) Pittsburgh Healthcare System, Pittsburgh, PA; ${ }^{2}$ Department of \\ Physical Medicine and Rehabilitation Assistive Technology, Hunter Holmes McGuire VA Medical Center, Richmond, VA
}

\begin{abstract}
The design of the mobility enhancement robotic wheelchair (MEBot) was based on input from electric powered wheelchair (EPW) users regarding the conditions they encounter when driving in both indoor and outdoor environments that may affect their safety and result in them becoming immobilized, tipping over, or falling out of their wheelchair. Phase I involved conducting a participatory design study to understand the conditions and barriers EPW users found to be difficult to drive in/over. Phase II consisted of creating a computer-aided design (CAD) prototype EPW to provide indoor and outdoor mobility that addressed these conditions with advanced applications. Phase III involved demonstrating the advanced applications and gathering feedback from end users about the likelihood they would use the advanced applications. The CAD prototype incorporated advanced applications, including selfleveling, curb climbing, and traction control, that addressed the challenging conditions and barriers discussed with EPW users $(n=31)$ during the participatory design study. Feedback on the CAD design and applications in phase III from end users $(n=$ 12 ) showed a majority would use self-leveling $(83 \%)$, traction control (83\%), and curb climbing (75\%). The overall design of MEBot received positive feedback from EPW users. However, these opinions will need to be reevaluated through user trials as the design advances.
\end{abstract}

Key words: barriers, design, electric powered wheelchair, mobility, mobility enhancement, movement, robotics, traction control, transportation, wheelchair.

\section{INTRODUCTION}

The electric powered wheelchair (EPW) is an essential mobility device for people who have limited to no upper- and/or lower-limb movement, such as those diagnosed with spinal cord injury, cerebral palsy, amyotrophic lateral sclerosis, or muscular dystrophy [1-6]. In the United States, people with disabilities typically receive their EPWs through private health insurance, Medicaid, Medicare, vocational rehabilitation, or the Veterans Health Administration [7]. With the exception of vocational rehabilitation and the Veterans Health Administration, these funding sources do not provide funding for EPWs with capabilities that are not necessary for use within the home, such as speeds greater than $6 \mathrm{mph}$,

\footnotetext{
Abbreviations: $\mathrm{CAD}=$ computer-aided design, $\mathrm{CT}=$ Coding Analysis Toolkit, EPW = electric powered wheelchair, FWD = front wheel drive, MEBot = mobility enhancement robotic wheelchair, MWD = mid-wheel drive, PerMMA II = Personal Mobility and Manipulation Appliance II, RWD = rear wheel drive.

*Address all correspondence to Rory A. Cooper, PhD; Human Engineering Research Laboratories, VA Pittsburgh Healthcare System, 6425 Penn Ave, Suite 400, Pittsburgh, PA 15206; 412-822-3700; fax: 412-822-3699.

Email: rcooper@pitt.edu

http://dx.doi.org/10.1682/JRRD.2014.11.0278
} 
climbing curbs greater than 3 in., and having a range of $16 \mathrm{mi}$ per charge because they do not meet the coverage criteria outlined in the National Coverage Determination for Mobility Assistive Equipment and the Local Coverage Determination for Power Mobility Devices developed for Medicare [8-9]. EPWs that meet the coverage criteria are designed for indoor usage. As a result, they often lack stability and cause an increase in safety concerns when used outside of the home, especially over uneven terrain. If users need a mobility device inside of their home, they would also need one when they leave their home. Thus, many users must also use their EPW when going to work, doctor's appointments, the grocery store, or a friend's house. Unfortunately, when EPW users venture into the outdoor environment, they may encounter conditions or obstacles that may lead to them becoming stuck or tipping over their wheelchair, causing serious injury or death [10]. Such conditions may include uneven terrain, steep slopes, slippery surfaces, cross slopes, and architectural obstacles such as curbs and steps [11-12].

According to the 2010 U.S. Census, 3.6 million people aged $15 \mathrm{yr}$ and older used a wheelchair [13], of which an estimated 15 percent, or 540,000, use an EPW [14]. The number of EPW users is expected to increase due to the aging baby boomer population and returning troops from the Afghanistan and Iraq wars. As a result, the number of accidents is also expected to rise. One study found that most common accidents were caused by loss of traction, being immobilized, or loss of stability [11]. Another study found that 87.8 percent of 95 participants had experienced a tip or fall up to $3 \mathrm{yr}$ prior to participating in the study [15]. Therefore, the objectives of this project were to understand the conditions and barriers EPW users find difficult to drive in/over in the outdoor environment (phase I), create a computer-aided design (CAD) prototype of an EPW with advanced features that increase the users' safety and ease navigation when encountering such conditions and barriers (phase II), and validate the newly designed EPW and its advanced features by gathering further input from EPW users (phase III).

\section{METHODS}

\section{Phase I}

Users of EPWs rely heavily on their mobility devices to transport them to where they need to be as safely and independently as possible. Unfortunately, there are instances in which they may encounter hazardous terrain or architectural barriers. In order to gain a deeper understanding of the conditions EPW users encounter, a research study was performed in which active wheelchair users were asked to complete a questionnaire about their demographic information, type of EPW used, and driving experience in 23 different driving conditions. The 23 conditions were identified based on feedback from experienced EPW users and licensed professionals in wheelchair provision. Additionally, a focus group discussion took place where they were asked to further discuss difficult driving scenarios they had encountered. The interviews and focus groups were held between September 2008 and July 2009.

\section{Participants}

Ethical approval for this study was obtained from the institutional review board of the Department of Veterans Affairs Pittsburgh Healthcare System, and all participants were asked to provide informed consent prior to enrollment in the study. For participants to be eligible to participate, they had to meet the following inclusion criteria: (1) the individual must use an EPW as a primary means of mobility, (2) the individual must actively use his or her EPW outside of the home at least three times a week, and (3) the individual must be over the age of 18 yr. Participants were recruited in the Pittsburgh area, at the National Disabled Veterans Winter Sports Clinic in Snowmass Village, Colorado, and at the National Veterans Wheelchair Games in Spokane, Washington. The participants in the Pittsburgh area were recruited through a registry of wheelchair users maintained by the Human Engineering Research Laboratories. The study did not focus on a specific disease or disability and no participants were excluded based on race, ethnicity, sex, or HIV status.

\section{Data Collection}

Questionnaire layout. The questionnaire consisted of four sections: (1) personal data, (2) demographics and self-assessment, (3) current wheelchair characteristics, and (4) driving scenarios. Section 1 identified the participant's sex, age, and ethnic origin. Section 2 identified impairment/disability, date of onset/injury, current work status, marital status, length of time using an EPW, length of time using current EPW, and number of days per week wheelchair was used outside of the home. Section 3 consisted of identifying the wheelchair model, manufacturer, date received, control method (e.g., joystick, head array, sip and puff), additional equipment (e.g., elevator, elevating leg rests, tilt-in-space), and drive wheel location (front wheel drive [FWD], mid-wheel drive [MWD], or 
rear wheel drive [RWD]). Section 4 consisted of 23 different driving conditions (Figure 1) and asked the participants to rate each based on degree of difficulty. The four levels of difficulty were (1) I can drive through this condition without any difficulty, (2) I have encountered this condition and it can be difficult to drive through, (3) I try to avoid this condition if I can, and (4) I have never encountered this condition.

Focus group procedure. All of the participants $(N=$ 31) provided informed consent prior to enrollment in the study. Each of the eight focus groups consisted of two to eight people and ranged from $30 \mathrm{~min}$ to $2 \mathrm{~h}$ depending on how many people participated and how many comments they offered. The discussions focused on the difficult driving situations participants encountered. If needed, more discussion was prompted by using the scenarios from the questionnaire. The discussions were audio recorded and were later transcribed and stripped of the 18 Health Insurance Portability and Accountability Act identifiers [16].

\section{Data Analysis}

The data collected from the questionnaires were entered into a Microsoft Excel (Redmond, Washington) spreadsheet and analyzed with conventional descriptive statistics such as frequencies, means, and standard deviations. The transcribed audio files were coded using two different methods to enhance validity.

The ratings for the ease of navigation of the 23 driving conditions were organized by wheelchair type to understand what conditions were most avoided based on the type of wheelchair. A percentage was calculated by taking the number of responses to a condition based on the wheelchair type and dividing by the total number of people with the same wheelchair type. This percentage was then compared with the other wheelchair types.

\begin{tabular}{|l|l|l|}
\hline \multicolumn{3}{|c|}{ DRIVING CONDITIONS } \\
\hline Uneven Terrain & Driving Down Steep Hills & $\begin{array}{l}\text { Dry Grass } \\
\text { Gravel }\end{array}$ \\
Curb Cuts & Hard Sand \\
Driving Up Steep Hills & Crowds of People & Soft Sand \\
Mud & Cross Slopes & Rain \\
Wet Grass & Cobblestone & Ramps \\
Turning on a Slope & Severe Cold & Driving at Night \\
Ice & One Wheel Off Ground & Heavy Carpet \\
Snow & Severe Heat & \\
\hline
\end{tabular}

Figure 1.

List of 23 driving conditions evaluated in questionnaire.
In an effort to increase the interrater reliability and eliminate any bias due to knowledge of the focus group contents, three researchers that were experts in the field of powered mobility performed the coding of the transcript. They performed the targeted coding using the online Coding Analysis Toolkit (CT) [17]. The CT is a free service of the Qualitative Data Analysis Program at the University of Pittsburgh and the College of Social and Behavioral Sciences at the University of Massachusetts Amherst. The coding is performed by reading blocks of text from the transcript and check-marking a predetermined code if the driving condition was mentioned as an obstacle. The results of the coding provide an understanding of the frequency users encounter difficult driving conditions or obstacles. The predetermined codes were the 23 driving conditions from section 4 of the questionnaire. The coded data were also analyzed for consistency with the results of the questionnaire.

In vivo coding was also performed on the transcript. In vivo coding is performed to create codes by directly taking blocks of text from the material as it is being read and without having predetermined codes. This method allows for a large amount of textual information to be summarized into the most important points [18]. A separate researcher performed an in vivo analysis that was given to the same three researchers that performed the targeted coding. These researchers then performed their own in vivo analysis while critiquing the first researcher's analysis. Therefore, the results of the in vivo coding consisted of the combined analysis of four researchers.

\section{Data Credibility}

Several different methods were used by the researchers to establish the credibility of the data and support the overall conclusions presented. First, the consistency of the participants' answers to section 4 (Driving Scenarios) was checked by overlaying the graphs of the conditions rated as Easy and Avoid. By asking the same question in opposite ways, the graph results were mirror images of each other, implying that the participants' answers were consistent. Second, the CT used for the targeted coding of the focus group transcripts included a statistical test for calculating Krippendorff alpha to determine the interrater reliability [19]. Krippendorff alpha scores of 0.8 and above are considered to have good agreement and scores between 0.6 and 0.8 are considered acceptable. Finally, the in vivo coding of the focus group transcripts were performed by multiple coders independently who then discussed similarities and differences in their coding. 


\section{Phase II}

The design of the mobility enhancement robotic wheelchair (MEBot) was driven by the input received during phase I. MEBot's design was also focused toward improving the capabilities and addressing the issues of the Personal Mobility and Manipulation Appliance II (PerMMA II) [20]. PerMMA II was developed as an obstacle-climbing wheelchair that could move in structured and unstructured environments and climb curbs up to 8 in. high. However, PerMMA II's design limited its capability when in unstructured environments, and it was only capable of climbing a 6 in. high curb. As a result, MEBot's design is an improvement of PerMMA II. The CAD prototype of MEBot was created using Solidworks 2012 (Dassault Systèmes; Waltham, Massachusetts).

\section{Phase III}

After the CAD prototype of MEBot was completed, an additional research study was performed to gather feedback about the design and advanced applications. Participants were asked to complete a questionnaire regarding their personal demographics, current EPW, training and accidents, and outdoor driving characteristics. The questionnaire also included items relevant to the participants' likelihood of using the advanced applications of MEBot that were demonstrated with videos and PerMMA II. At the time of the study, MEBot was not a manufactured working prototype. Therefore, the demonstrations used PerMMA II to provide a frame of reference for the MEBot.

\section{Participants}

The participants eligible for the participatory evaluation study had to meet the same inclusion criteria outlined for the participatory design study in phase I and took place in July 2014. The same participants from phase I were unavailable to participate in phase III because of the extended length of time between studies and different locations of the studies. As such, a total of 12 new EPW users were recruited for the phase III study. The participants were recruited through the registries developed by the Human Engineering Research Laboratories. Ethical approval was obtained from the institutional review board of the University of Pittsburgh and all participants provided informed consent prior to participating in the study.

\section{Data Collection}

Another questionnaire was used for the participatory evaluation study, which mirrored that of the participatory design study with the addition of a section regarding the likelihood that the participants would use the advanced MEBot applications. The questionnaire was split into five sections and included (1) personal demographics, (2) current wheelchair information, (3) EPW training and accidents, (4) outdoor driving characteristics, and (5) MEBot applications. Section 1 asked demographic questions about the participants' disability, education, employment, etc. Section 2 consisted of the wheelchair model, manufacturer, date received, control method (e.g., joystick, head array, sip and puff), additional equipment (e.g., elevator, elevating leg rests, tilt-in-space), and drive wheel location (FWD, MWD, or RWD). Section 3 asked participants about the training received when obtaining their current EPW and whether they had had any accidents. Section 4 consisted of questions regarding the places the participants visited in the past week. Section 4 also asked how many times the participants came across a terrain (concrete, gravel, dirt/mud, carpet, grass, or sand) or architectural barrier (curbs, ramps, cross slopes, curb cuts, or door thresholds) and the action they performed when they came across the terrain or barrier. The three action items were (1) avoided it, (2) went over it with help, and (3) went over it by myself. Section 5 asked the participants about the likelihood they would use each of the advanced applications of MEBot, including self-leveling, selectable drive wheel position, curb climbing, traction control, and two-wheel balance.

\section{RESULTS}

\section{Phase I}

\section{Questionnaire}

User demographics and wheelchair type. All 31 participants completed the questionnaire and participated in the focus group discussions. The results from the questionnaire revealed that the participants' average age was $55.8 \pm 9.1 \mathrm{yr}$, where a majority were male (84\%), had a spinal cord injury (71\%), and were retired because of their disability (58\%). Many of the participants were experienced wheelchair users, with an average of 13 yr using an EPW, and had been using their current EPW for an average of 3 yr. The type of wheelchair that the participants currently use consisted of mostly RWD and MWD, with 42 percent and 35 percent of the total, respectively.

Wheelchair driving conditions. The conditions with the greatest differences between the wheelchair types were mud, gravel, and cross slopes. For mud, 
approximately 70 percent of MWD and RWD users avoided it, while only 33 percent of FWD users did so. However, the difference between avoiding gravel for MWD and RWD users was much greater: 54 percent of RWD users avoided it, compared with MWD at 31 percent and FWD at 17 percent. As for cross slopes, RWD users were least likely to avoid them (31\%) compared with FWD (50\%) and MWD (62\%). More than 50 percent of the participants stated the following conditions were difficult: uneven terrain, gravel, driving up steep hills, mud, and wet grass. Additionally, the driving conditions that 50 percent of the participants avoided were mud, soft sand, ice, driving with one wheel off of the ground, rain, and cross slopes.

\section{Focus Group Transcript}

Targeted coding. Targeted coding was performed by three researchers using predetermined codes that were obtained from the questionnaire's driving condition categories (Figure 1). They were instructed to code an item when one of the driving condition categories was referenced as an obstacle in the focus group transcript. The results of the targeted coding provided insight into the driving conditions mentioned, specifically those that were mentioned 50 percent more frequently than the others, including uneven terrain, driving up and down steep hills, cross slopes, gravel, curb cuts, and ramps. The overall score from the Krippendorff alpha test for interrater reliability was 0.61 , which is within the acceptable range. Therefore, the predetermined codes used for the targeted coding can be considered reliable enough to draw conclusions from.

In vivo coding. The in vivo coding by the four researchers resulted in 19 codes. These codes were then grouped into five high-level categories, including hard surfaces, soft surfaces, angled surfaces, adverse conditions, and training and accidents to better define the overall themes. Hard surfaces included sidewalks, curb cuts, potholes, speed bumps, and cobblestones; soft surfaces included dirt and mud, sand, gravel, and grass; angled surfaces included hills, cross slopes, and ramps; and adverse conditions included snow/ice, rain/wet, heat/ cold, crowds of people, and nighttime.

Table 1 provides a breakdown of the descriptions participants had difficulty with for soft surfaces and

Table 1.

Soft and angled surfaces descriptions.

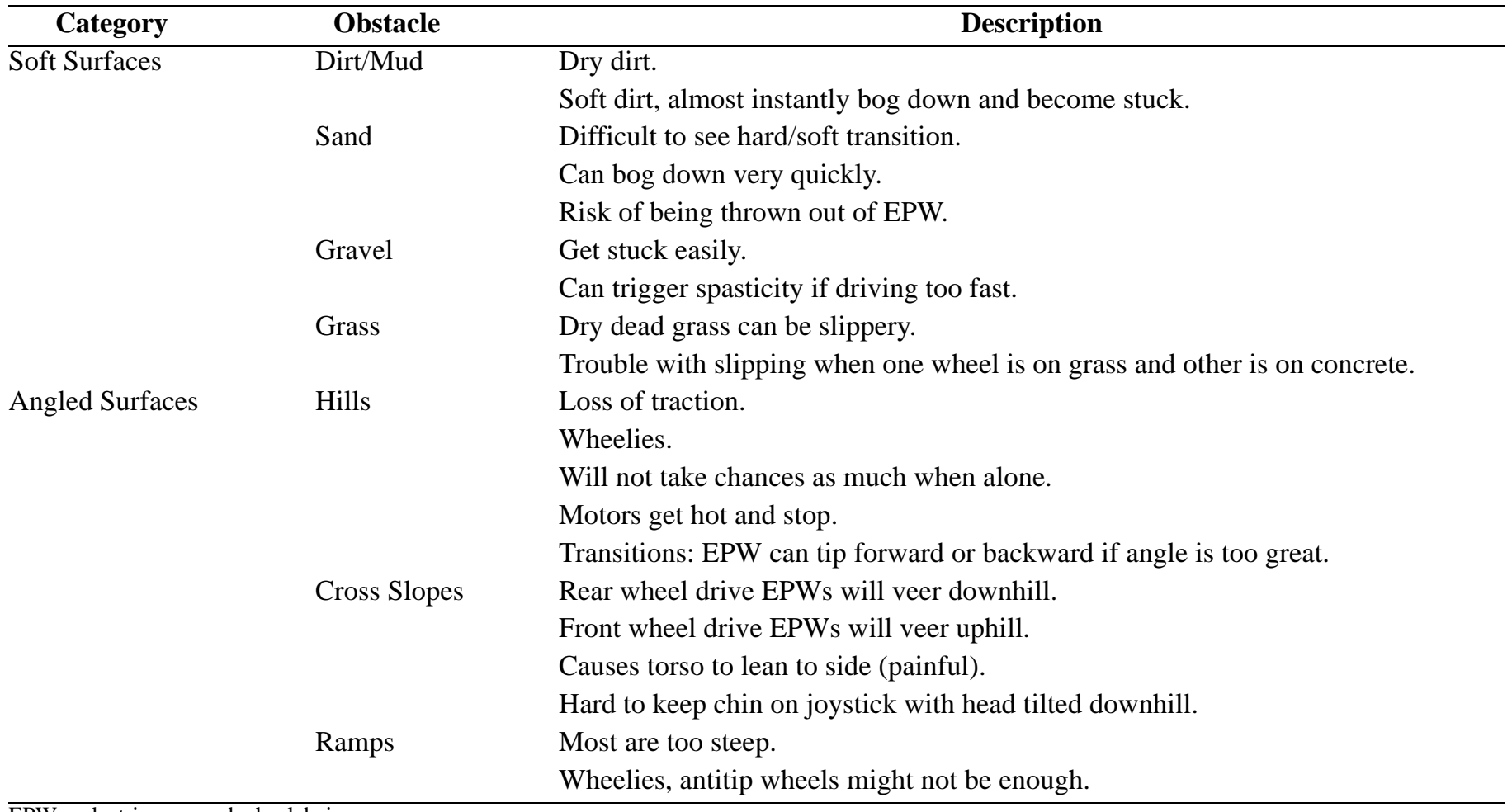


angled surfaces broken down into four and three subcategories, respectively.

\section{Phase II}

The MEBot (Figure 2) was designed based on feedback from the participatory design study and development of the PerMMA II (Figure 3) [12,20-21]. Several advanced applications were developed to improve the outdoor capabilities of an EPW, including selectable driving wheel location [20], self-leveling [20], curb climbing [22], traction control [23], and two wheel balance.

\section{Driving Wheel Positioning}

MEBot's development of driving wheel position selection allows the user to configure MEBot as a FWD, MWD, or RWD EPW [20]. The different configurations affect the EPW's maneuverability and driving dynamics in addition to determining its stability and ease of operation with respect to the EPW's center of gravity. The driving wheels can be positioned 7 in. forward and backward from the mid-wheel position (Figure 4).

\section{Self-Leveling}

The self-leveling application utilizes each of MEBot's six wheels' ability to move up and down via pneumatic

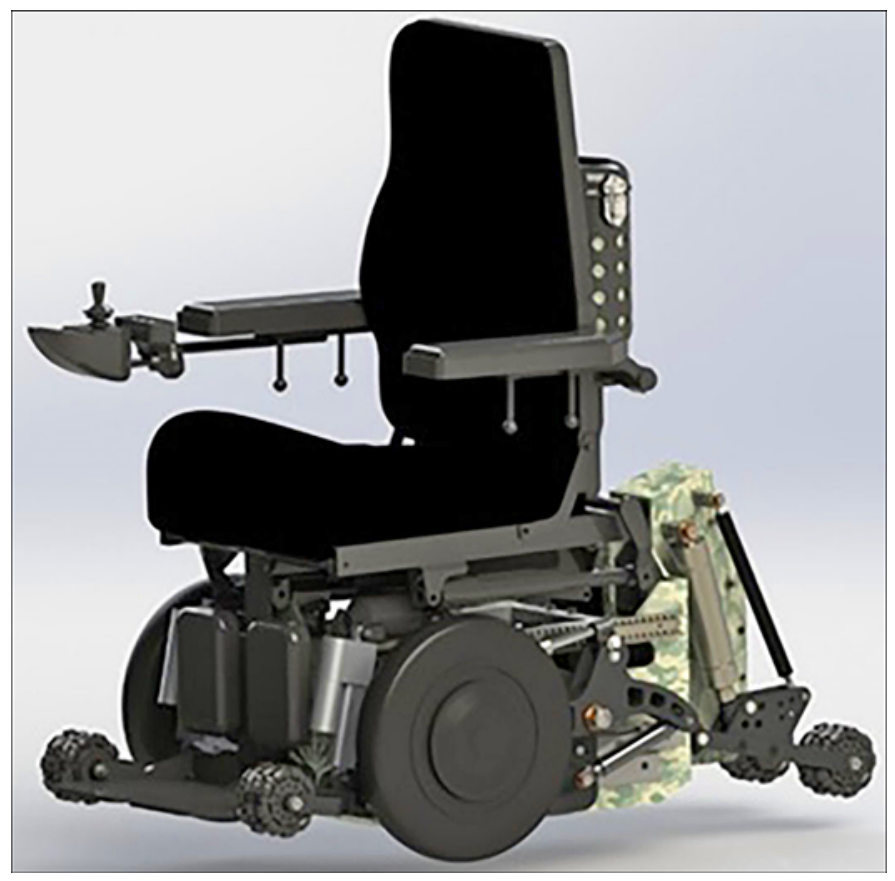

Figure 2.

Mobility enhancement robotic wheelchair prototype design. actuators. This vertical motion allows MEBot to change its center of gravity by maintaining the same position of the seating system while driving on slopes or uneven terrain. The maximum slopes and cross slopes on which MEBot can perform self-leveling are $16.8^{\circ}$ and $20.3^{\circ}$, respectively (Figure 5).

\section{Traction Control}

The traction control application senses any slippage in the driving wheels and automatically decreases the speed of the slipping wheel in order for the user to maintain the desired path of travel [23].

\section{Curb Climbing}

The curb climbing application uses the vertical motion of each of MEBot's six wheels and the horizontal motion of the driving wheels [22]. Once the curb climbing application is activated, MEBot automatically performs a sequence of steps to climb up or down curbs up to 8 in. high.

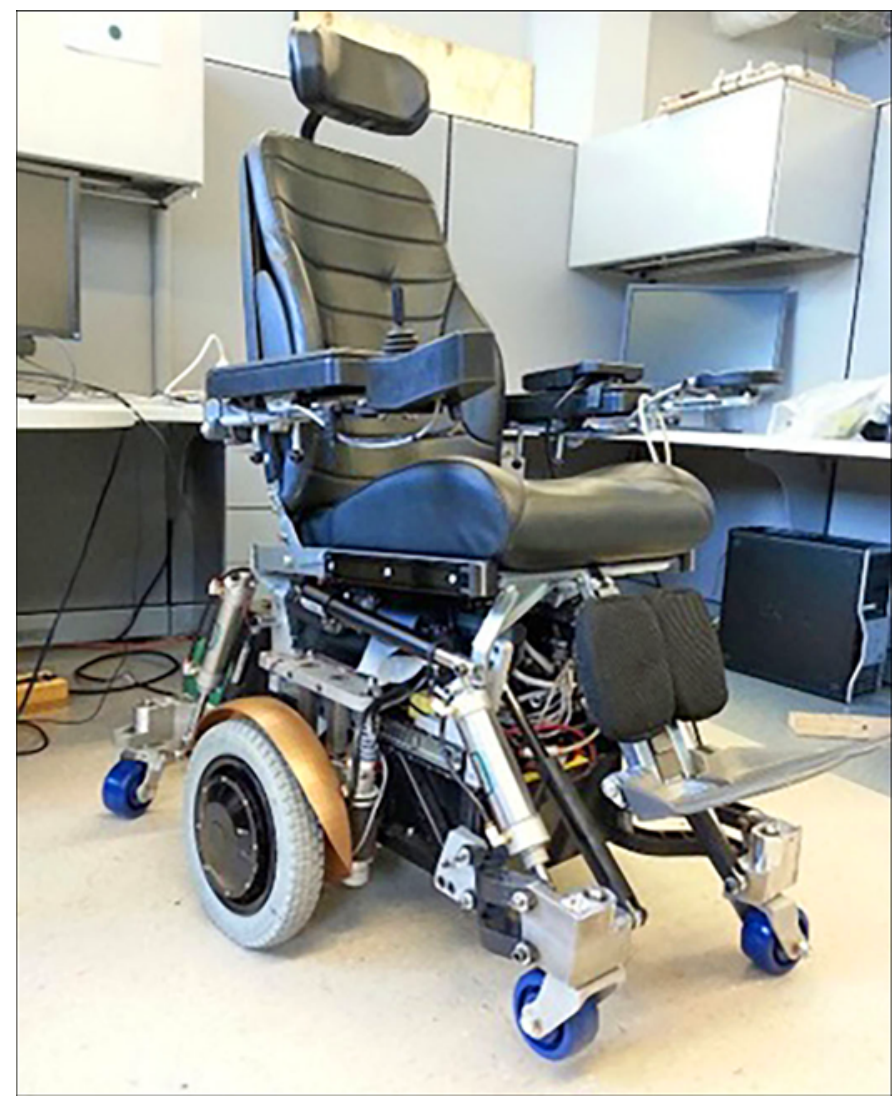

Figure 3.

Personal Mobility and Manipulation Appliance II. 


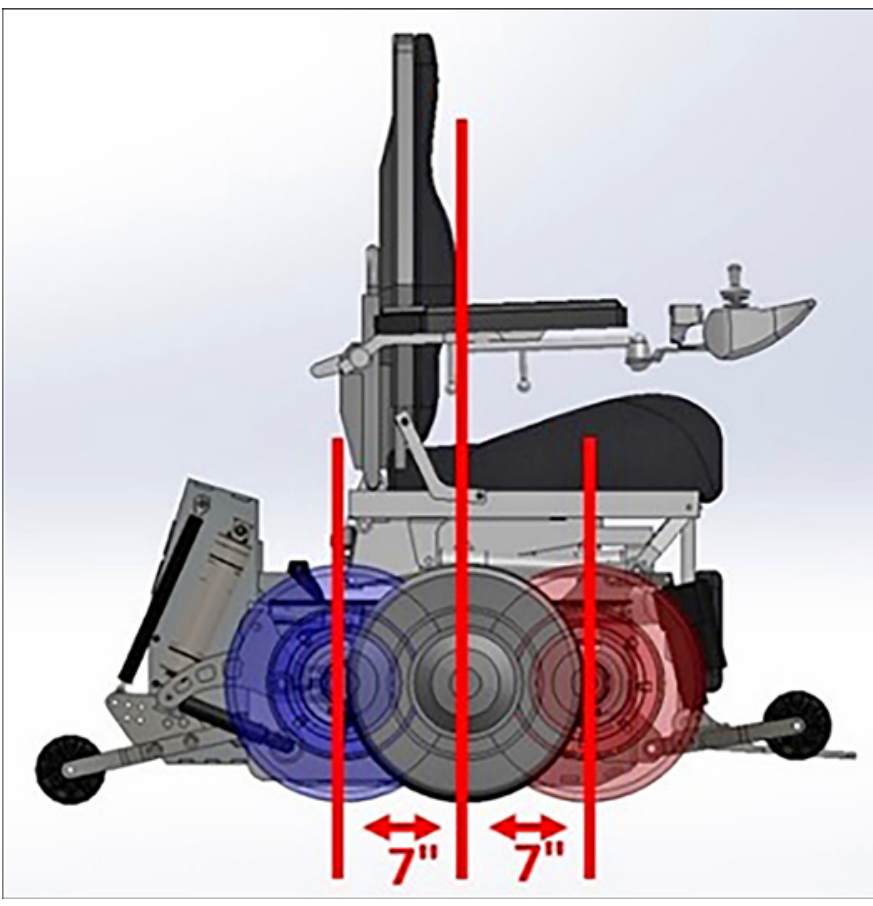

Figure 4.

Driving wheel position limits.

In order for the user to safely cross the street, climb the curb, and get out of the pathway of traffic, the entire process is completed in an estimated $30 \mathrm{~s}$. The curb climbing sequence is completed over a series of seven steps (Figure 6). The steps are as follows: (1) elevate MEBot 8 in., (2) drive forward until the drive wheel touches the curb, (3) extend the front casters, (4) begin driving forward while lifting the drive wheels, (5) continue driving forward until the driving wheels are on top of the curb, (6) continue driving forward until rear casters contact the curb, and (7) lift rear casters on top of the curb.

\section{Two Wheel Balance}

The two wheel balance application allows MEBot to balance on its two driving wheels similar to a Segway [24]. Several sensors are used to detect changes in MEBot's center of gravity. MEBot then moves the driving wheels to counteract the center of gravity change in order to maintain its balance.

\section{Phase III}

\section{User Demographics and Wheelchair Type}

The questionnaire results showed that the participants were almost split between male (58.3\%) and female

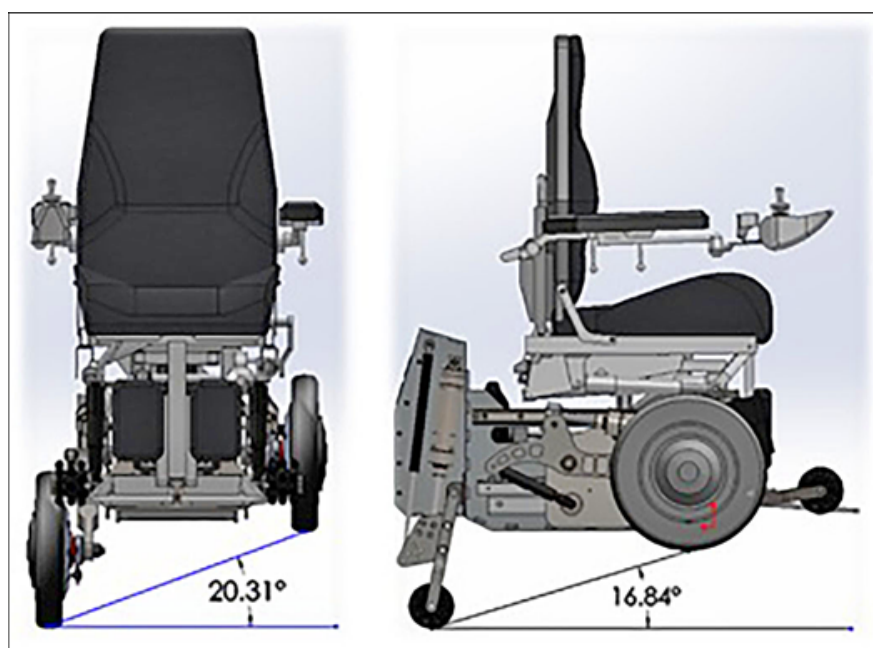

Figure 5.

Maximum cross slope (left) and up/down slope (right) angles.

(41.7\%), with an average age of $46.9 \pm 16.0 \mathrm{yr}$; over onethird of them worked full time outside of their home (38.5\%), and one-half had a spinal cord injury (50\%). The participants were experienced users with an average of 16.3 yr using an EPW, had been using their current EPW for an average of $3.3 \mathrm{yr}$, and spent an average of $14.6 \mathrm{~h}$ per day in their EPW. Unlike the participatory design study in which a majority of the participants used a RWD or MWD wheelchair, the participants of the participatory evaluation study mostly used a MWD and FWD, with 50 percent and 41 percent of the total, respectively.

\section{Wheelchair Driving Characteristics}

The places that the participants visited during the past week supported the fact that they were active EPW users, and the most frequented places visited were restaurants, work, grocery stores, or the doctor's office.

Table 2 shows the obstacles and terrain they encountered and the action they took when they encountered it. The most encountered obstacle or terrain was traversing up and down ramps, concrete, curb cuts, and door thresholds. The majority of the participants went over their most encountered obstacle or terrain by themselves. For the least encountered obstacle or terrain of sand, dirt/ mud, or gravel, the participants were split between avoiding it and going over it with help. 


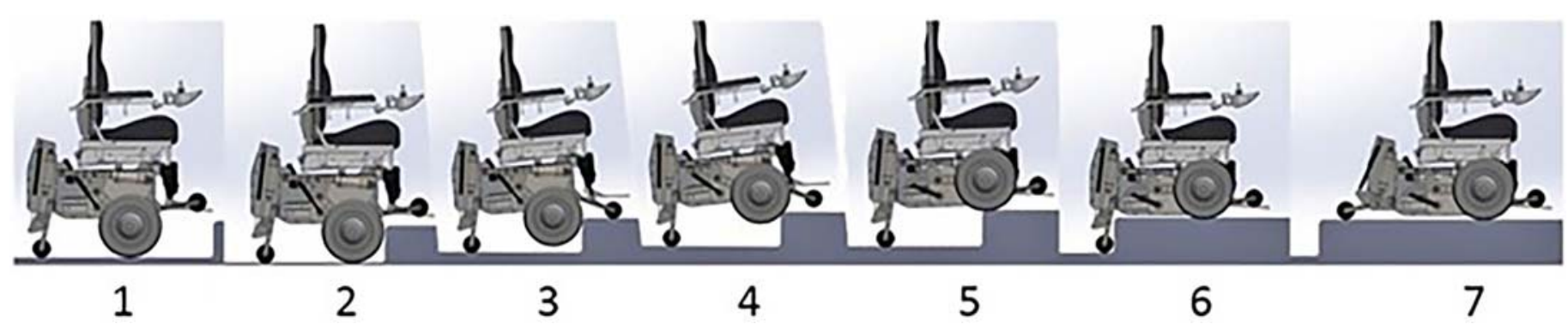

Figure 6.

Curb climbing sequence.

Mobility Enhancement Robotic Wheelchair Applications

The participants rated the likelihood they would use each of the advanced applications after the videos and PerMMA II demonstrations were shown. The results showed a majority of the participants would very likely use self-leveling (83\%), traction control (83\%), and curb climbing (75\%), while the selectable driving wheel position and two wheel balance applications were less likely to be used (Table 3).

\section{DISCUSSION}

\section{Phase I}

The design of MEBot was guided by input from the participants in phase I and was then validated through feedback received in phase III. The overall results of phase I brought to attention the major concerns EPW users encounter when driving in the outdoor environment. The least severe of the concerns is slipping because it is possible to recover from it if the correct techniques are known and applied. A worse concern would be getting stuck because the user is completely immobilized and unable to get away from dangers like rain, cold, or vehicles. The worst of the concerns is tipping of the wheelchair when driving up steep hills or over uneven terrain because the wheelchair stability is jeopardized [25]. With about 85,000 serious wheelchair accidents occurring annually, the number of accidents is expected to rise as the need for EPWs increases [26].

Table 2.

Obstacle frequency and action taken.

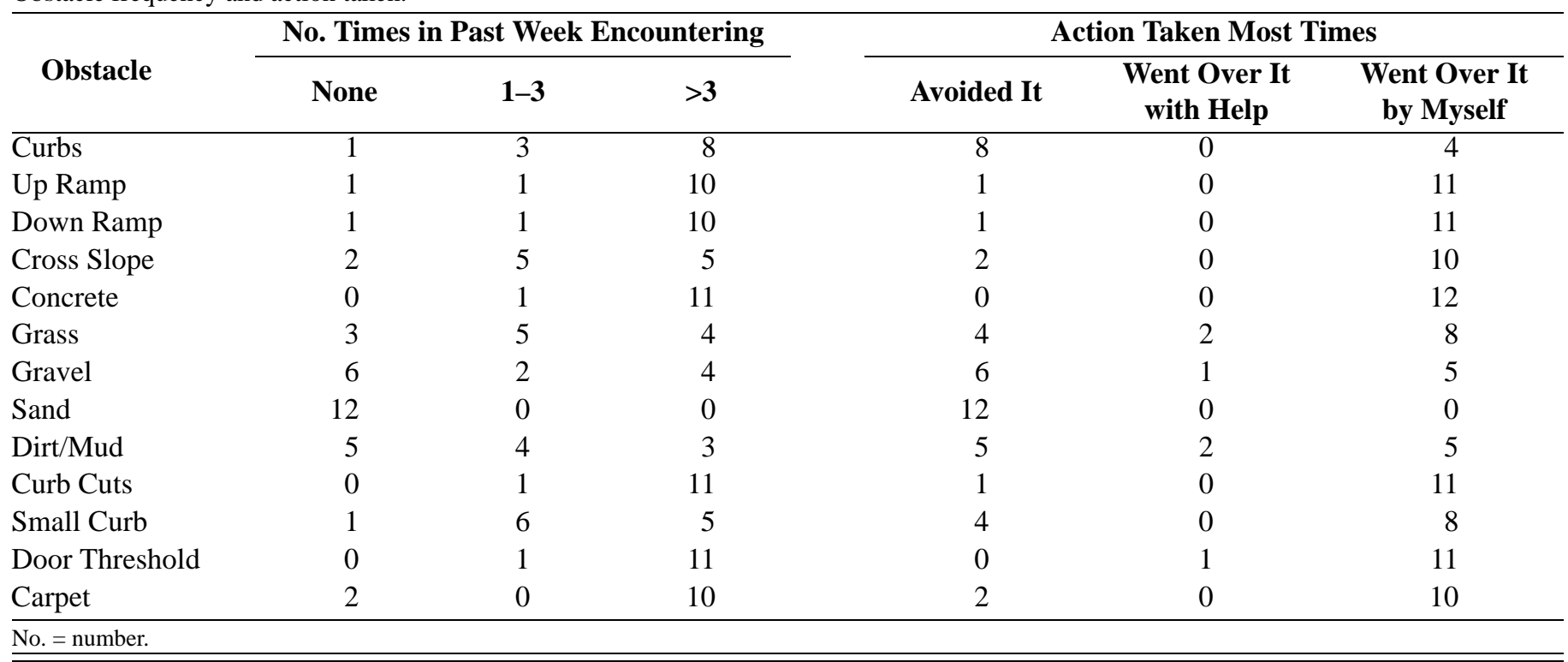


Table 3.

Likelihood to use mobility enhancement robotic wheelchair applications.

\begin{tabular}{lcccc}
\hline \multicolumn{1}{c}{ Application } & Very Unlikely & Unlikely & Likely & Very Likely \\
\hline Self-Leveling & - & - & 2 & 10 \\
Selectable Driving Wheel Position & - & 5 & 3 & 4 \\
Curb Climbing & - & - & 2 & 9 \\
Traction Control & - & 1 & 5 & 3 \\
Two Wheel Balance & 2 & - & 3 & 3 \\
\hline \hline
\end{tabular}

\section{Phase II}

\section{Drive Wheel Positioning}

Each configuration has pros and cons. MWD EPWs typically have the highest maneuverability due to the drive wheels being placed in the center of the wheelchair, which allows for turning $360^{\circ}$ within its own wheelbase. However, if either of the two front casters or two rear casters experience a sideways force, the chair could veer off course. The second most maneuverable EPWs are FWD EPWs. They perform better when climbing obstacles or going over rough terrain since the larger diameter driving wheels are the first to contact the obstacle. FWD provides the greatest stability when traveling down slopes but is difficult to maneuver when driving over uneven terrain or at higher speeds since the center of gravity is toward the rear of the chair. The RWD EPW tends to be the most stable at higher speeds, simplest to control, and more stable when traveling up slopes but lacks the maneuverability of a MWD or FWD EPW.

\section{Self-Leveling}

The self-leveling application increases the stability, comfort, and safety of the user when driving up slopes, down slopes, across slopes, or over uneven terrain. Selfleveling automatically adjusts MEBot's center of gravity, which improves its stability on slopes, thus decreasing the likelihood of the user tipping his or her EPW. Another benefit of self-leveling is the decrease in the users' feeling of falling forward when going down a slope or the decrease in pressure on their torso when traveling on a cross slope. Most importantly, the user's overall safety is improved in comparison to other wheelchairs when driving on slopes or uneven terrain.

\section{Traction Control}

Wet, icy, or snowy surfaces can cause the EPW to slip or lose traction on one of the driving wheels, which may cause the EPW to veer off course. This veering can cause users to drive off of the desired path or sidewalk, which may lead to tipping or falling out of their wheelchair, resulting in serious injury. However, the traction control application automatically senses the wheel slipping and maintains the users' desired path, thus increasing their safety in slippery conditions.

\section{Curb Climbing}

Many EPWs are unable to climb curbs, specifically large curbs up to 8 in. in height. As a result, users rely on curb cuts when crossing the street. A curb cut is a ramp cut into a street curb that allows for a smooth transition down from a sidewalk to a street, instead of ending with a curb and dropping roughly 4 to 6 in. Unfortunately, many users have encountered a situation in which a curb cut was not available, the curb cut was blocked, or the curb cut was in bad condition [27-29]. In some cases, the curb cuts were only on one side of the street or were indirectly across from each other. Therefore, the alternative was to drive in the street when a curb cut was not available, thus putting user's safety in jeopardy [27]. The curb climbing application removes the need for a user to search for a curb cut in the event that one is not available in the vicinity where they would like to get up or down a curb.

\section{Two Wheel Balance}

When users encounter terrain such as mud, wet grass, or loose gravel, they may lose traction and become stuck due to the distribution of the weight of the wheelchair onto the caster wheels and driving wheels. In many cases, the caster wheels dig into the surface due to their small size. The two wheel balance application places all of the wheelchair's weight onto the two driving wheels, thus removing the weight being placed on the caster wheels. As a result, the driving wheels have improved traction because of the increase in weight being placed on them, which could allow the user to become unstuck independently and avoid being stranded. 


\section{Phase III}

Once the applications were developed and design was completed, phase III validated MEBot's design and development of the advanced applications. Overall, the results showed that the participants in both phase I and phase III experienced similar difficulties when driving in sand, gravel, and mud and usually avoided steep slopes and curbs. At least 75 percent of the participants of phase III stated that they would very likely use the applications of self-leveling, curb climbing, and traction control. However, it should be noted that a majority of the participants lived in the city, which may have affected the applications they would most likely use due to the types of terrains and obstacles they encounter on a daily basis.

\section{Wheelchair Driving Characteristics}

The differences in the types of terrain users avoided based on their wheelchair type yielded interesting results. FWD users avoided mud, gravel, and cross slopes less than MWD and RWD users. One possible theory for this is the design of a FWD when compared with MWD and RWD EPWs; the large driving wheels are in the front, which removes the possibility of the front casters digging into the mud. The same cannot be said for gravel; RWD users mostly avoided it compared with FWD and MWD users. The difference may be due to the difference in weight distribution between the RWD, FWD, and MWD. The RWD's weight is typically more forward, which may cause the front casters to dig into the gravel, unlike the MWD where the weight is more centered.

\section{Mobility Enhancement Robotic Wheelchair Applications}

The three applications that the majority of the participants of the phase III study liked theoretically have the greatest potential to improve their safety and independence, unlike the applications of being able to change the drive wheel position and two wheel balance. Several of the participants stated that they would not use the ability to change the drive wheel position because they would have to adapt to the changes in maneuverability and driving style of the different drive wheel configurations each time they changed their position. As for the two wheel balance application, the participants did not see a need to balance on two wheels and were concerned with the stability of MEBot when doing so.

\section{CONCLUSIONS}

The development of advanced applications and prototype design of MEBot addressed the hazardous driving conditions and concerns EPW users encounter in the outdoor environment in addition to improving and addressing the issues of PerMMA II. As a result of the major concerns found during phase I, the design of MEBot was focused toward developing advanced applications that the user could utilize to overcome the obstacles and situations of concern. For example, slipping in wet grass, snow, ice, or rain was addressed with the application of traction control and two wheel balance, which can be used to prevent the user from becoming stuck or allow the user to become unstuck in mud, soft sand, wet grass, or gravel. Furthermore, the selectable drive wheel positioning can also be used in the event that the user does become stuck by allowing him or her to relocate the driving wheels to regain traction. Finally, the worst concern of losing stability and tipping over was addressed with the self-leveling application, which automatically adjusts the seating system and center of gravity based on the uneven terrain or slope the user drives up, down, or across. The curb climbing application addresses the concern of tipping over when going up or down high curbs due to the lack of or condition of a curb cut. With the inclusion of advanced applications, MEBot provides users with an increased sense of safety, feeling of independence, and quality of life.

\section{ACKNOWLEDGMENTS}

\section{Author Contributions:}

Study concept and design: B. Daveler, B. Salatin, H. Wang, R. A. Cooper. Acquisition of data: B. Daveler, B. Salatin.

Analysis and interpretation of data: B. Daveler, B. Salatin, G. G. Grindle, J. Candiotti, H. Wang, R. A. Cooper.

Drafting of manuscript: B. Daveler.

Critical revision of manuscript for important intellectual content:

B. Daveler, H. Wang, R. A. Cooper.

Statistical analysis: B. Daveler, B. Salatin.

Obtained funding: H. Wang, R. A. Cooper.

Administrative, technical, or material support: G. G. Grindle, J. Candiotti, H. Wang, R. A. Cooper.

Study supervision: G. G. Grindle, H. Wang, R. A. Cooper.

Financial Disclosures: The authors have declared that no competing interests exist.

Funding/Support: This material was based on work supported by the Department of Veterans Affairs Rehabilitation Research and Development Center of Excellence (grant B9250-C), and the National Science 
Foundation Interdisciplinary Research Training in Rehabilitation Engineering (grant DGE1144584), and the National Science Foundation Quality of Life Engineering Research Center (grant EEC0540865). Institutional Review: Ethical approval for this study was obtained from the institutional review board of the Department of Veterans Affairs Pittsburgh Healthcare System, and all participants were asked to provide informed consent prior to enrollment in the study.

Participant Follow-Up: The authors do not plan to inform the participants of the publication of this study.

\section{REFERENCES}

1. Anderson KD. Targeting recovery: Priorities of the spinal cord-injured population. J Neurotrauma. 2004;21(10): 1371-83. [PMID:15672628] http://dx.doi.org/10.1089/neu.2004.21.1371

2. Wood-Dauphinée S, Exner G, Group SC. Quality of life in patients with spinal cord injury-Basic issues, assessment, and recommendations. Restorative Neurol Neurosci. 2012; 20(3-4):135-49. [PMID:12454362]

3. Ward AL, Sanjak M, Duffy K, Bravver E, Williams N, Nichols M, Brooks BR. Power wheelchair prescription, utilization, satisfaction, and costs for patients with amyotropic lateral sclerosis: preliminary data for evidence-based guidelines. Arch Phys Med Rehabil. 2010;91(2):268-72.

[PMID:20159132] http://dx.doi.org/10.1016/j.apmr.2009.10.023

4. Cowan RE, Fregly BJ, Boninger ML, Chan L, Rodgers MM, Reinkensmeyer DJ. Recent trends in assistive technology for mobility. J Neuroeng Rehabil. 2012;9:20. [PMID:22520500] http://dx.doi.org/10.1186/1743-0003-9-20

5. Evans S, Neophytou C, de Souza L, Frank AO. Young people's experiences using electric powered indoor-outdoor wheelchairs (EPIOCs): Potential for enhancing users' development? Disabil Rehabil. 2007;29(16):1281-94. [PMID:17654003] http://dx.doi.org/10.1080/09638280600964406

6. Murphy KP, Molnar GE, Lankasky K. Employment and social issues in adults with cerebral palsy. Arch Phys Med Rehabil. 2000;81(6):807-11. [PMID:10857528] http://dx.doi.org/10.1016/S0003-9993(00)90115-1

7. Buning ME, Schmeler MR, Crane B. Funding for wheelchairs [Internet]. Pittsburgh (PA): WheelchairNet; 2006. Available from:

http://www.wheelchairnet.org/wcn prodserv/funding/ funding.html\#anchor10306817

8. Office of Inspector General. Most power wheelchairs in the Medicare program did not meet medical necessity guidelines. Washington (DC): Department of Health \& Human Services; 2011.
9. Sunrise Medical. Medicare power wheelchair codes. [Internet]. Fresno (CA): Sunrise Medical; 2015. Available from: http://marketing.sunrisemedical.com/Funding/documents/ FundingHandout.PDF

10. Xiang H, Chany A-M, Smith GA. Wheelchair related injuries treated in US emergency departments. Inj Prev. 2006;12(1):8-11. [PMID:16461412] http://dx.doi.org/10.1136/ip.2005.010033

11. Salatin B. Electric powered wheelchair driving outdoors: The identification of driving obstacles \& strategies and the development of an advanced controller. Pittsburgh (PA): University of Pittsburgh; 2011.

12. Cooper RA, Grindle G, Vazquez J, Xu J, Wang H, Candiotti J, Chung C, Salatin B, Houston E, Kelleher A, Cooper R. Personal mobility and manipulation appliance-design, development, and initial testing. IEEE. 2012;100(8):2505-11.

13. Brault MW. Americans with disabilities: 2010. Current population reports [Internet]. Washington (DC): U.S. Census Bureau; 2012 [cited 2015 May 24; updated 2012 Jul]. Available from: http://www.census.gov/prod/2012pubs/p70-131.pdf

14. Cooper RA, Cooper R, Boninger ML. Trends and issues in wheelchair technologies. Assist Technol. 2008;20(2):61-72. [PMID:18646429] http://dx.doi.org/10.1080/10400435.2008.10131933

15. Chen WY, Jang Y, Wang JD, Huang WN, Chang CC, Mao HF, Wang YH. Wheelchair-related accidents: Relationship with wheelchair-using behavior in active community wheelchair users. Arch Phys Med Rehabil. 2011;92(6): 892-98. [PMID:21621665] http://dx.doi.org/10.1016/j.apmr.2011.01.008

16. Guidance regarding methods for de-identification of protected health information in accordance with the Health Insurance Portability and Accountability Act (HIPAA) privacy rule [Internet]. Washington (DC): U.S. Department of Health and Human Services; 2015. Available from: http://www.hhs.gov/ocr/privacy/hipaa/understanding/ coveredentities/De-identification/guidance.html

17. University of Pittsburgh, University of Massachusetts Amherst. Coding Analysis Toolkit [Internet]. Pittsburgh (PA): University of Pittsburgh; 2010. Available from: http://cat.ucsur.pitt.edu

18. King A. In vivo coding. In: Given LM. The Sage encyclopedia of qualitative research methods. Los Angeles (CA): SAGE Publications; 2008. p. 473-74.

19. Hayes AF, Krippendorff K. Answering the call for a standard reliability measure for coding data. Commun Meth Meas. 2007;1(1):77-89.

20. Wang H, Candiotti J, Shino M, Chung CS, Grindle GG, Ding D, Cooper RA. Development of an advanced mobile base for personal mobility and manipulation appliance generation II robotic wheelchair. J Spinal Cord Med. 2013; 
JRRD, Volume 52, Number 6, 2015

36(4):333-46. [PMID:23820149]

http://dx.doi.org/10.1179/2045772313Y.0000000094

21. Wang H, Grindle GG, Candiotti J, Shino CC, Motoki S, Houston E, Cooper RA. The Personal Mobility and Manipulation Appliance (PerMMA): A robotic wheelchair with advanced mobility and manipulation. Conf Proc IEEE Eng Med Biol Soc. 2012;2012:3324-27. [PMID:23366637]

22. Wang H, Candiotti J, Chung C, Shino M, Cooper RA. Design and development of a step climbing sequence for a novel electric powered wheelchair. Proceedings of the Rehabilitation Engineering and Assistive Technology Society of North America Conference; 2012 Jun 28-Jul 3; Baltimore, MD.

23. Wang H, Salatin B, Grindle GG, Ding D, Cooper RA. Realtime model based electrical powered wheelchair control. Med Eng Phys. 2009;31(10):1244-54. [PMID:19733494] http://dx.doi.org/10.1016/j.medengphy.2009.08.002

24. Segway [Internet]. Bedford (NH): Segway; 2015. Available from: http://www.segway.com/

25. Kirby RL, Sampson MT, Thoren FA, MacLeod DA. Wheelchair stability: Effect of body position. J Rehabil Res Dev. 1995;32(4):367-72. [PMID:8770801]

26. Kirby RL, MacLeod DA. Wheelchair-related injuries reported to the National Electronic Injury Surveillance System: An update. Proceedings of the RESNA Annual Conference; 2001 Jun 22-26; Reno, NV.

27. Rosenberg DE, Huang DL, Simonovich SD, Belza B. Outdoor built environment barriers and facilitators to activity among midlife and older adults with mobility disabilities. Gerontologist. 2013;53(2):268-79. [PMID:23010096]

http://dx.doi.org/10.1093/geront/gns119

28. Gaal RP, Rebholtz N, Hotchkiss RD, Pfaelzer PF. Wheelchair rider injuries: Causes and consequences for wheelchair design and selection. J Rehabil Res Dev. 1997; 34(1):58-71. [PMID:9021626]

29. Kirchner CE, Gerber EG, Smith BC. Designed to deter. Community barriers to physical activity for people with visual or motor impairments. Am J Prev Med. 2008;34(4): 349-52. [PMID:18374250]

http://dx.doi.org/10.1016/j.amepre.2008.01.005

Submitted for publication November 7, 2014. Accepted in revised form May 20, 2015.

This article and any supplementary material should be cited as follows:

Daveler B, Salatin B, Grindle GG, Candiotti J, Wang H, Cooper RA. Participatory design and validation of mobility enhancement robotic wheelchair. J Rehabil Res Dev. 2015;52(6):739-50.

http://dx.doi.org/10.1682/JRRD.2014.11.0278

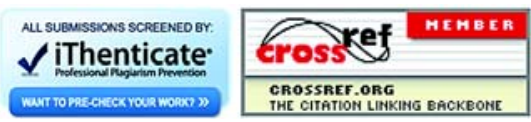

